非常に大きく，一応の比較の目安として求めた梁理論 によるものの約 4 倍近くに及んていることは注目に值 する.䋎横比が大であれば; この比率は低下して来る であるうと思われる.

一例であるので, スパン, 幅, 後退角が後縁の附根 の応力集中率に如何に影餐するかは分らない．したが って扔の扔のの場合について計算する必要があり，そ の結果から簡便な計算式を求めておけば設計等には便 利であろうと思われる.

\section{交暒}

1）下記の論文のReferenceに六十数篇の坔文名が記されている M. Williams: A Review of Certain Analyeis Methods for Swept-Wing Structures, Jour. Aero. Sei., 1952/9.

2) E. Reissner and M. Stein: Tortion and Trangverse Bending of Cantilever Plate, N.A.C.A. T.N. No. 2369.

3) H. Martin : On the Deflection of Swept Cantilevered Surfaces, Jour. Aero. Sci., 1951/12.

4）鈴木真一：後退解を有する海板の固有振助数について。日本 航空学会緿, 1957/3.

\title{
On the Effect of Free-Stream Turbulence on the Structure of Turbulent Wake*
}

\author{
Hiroyuki KoMODA ${ }^{\text {*k }}$
}

\section{Summary}

With a view to clarifying the effect of free-stream turbulence on the structure of a turbulent wake, hot-wire experiments were carried out in the wake behind a circular cylinder of 1-millimeter diameter in an air stream of velocity 10 meters per second. The measurements were made for the two cases; the one when the free stream was undisturbed and the other when it was disturbed by inserting a grid in such a way that the resulting turbulence was of the scale comparable to the width of wake.

Determinations were made of the mean velocity $U$ and quantities pertinent to the velocity fluctuations such as $\overline{u^{2}}, \overline{(\partial u / \partial x)^{2}}, \overline{u^{4}}$ and $\overline{u v}$. It was found that the effect of free-stream turbulence increased the turbulent intensity in the wake. Moreover, the structure of large eddies responsible for $\overline{u v}$ and $\overline{u^{4}}$ appeared to be scarcely affected, while that of small eddies pertinent to $\overline{(\partial u / \partial x)^{2}}$ noticeably affected at far distances downstream. These circumstances seem to suggest the rapid approach of large eddies toward a structural equilibrium.

\section{Introduction}

Systematic study of turbulent wake owes chiefly to Townsend ${ }^{(1,2), 3), 4), 5)}$, who has revealed some important features pertinent to the wake flow. One of these is the intermittent nature of turbulent flow which has also been discovered by Corrsines in the case of turbulent jet. Furthermore, Townsend was successful in predicting the distribution of mean velocity for various types of free turbulent shear flows by using the conception of intermittency above mentioned and the assumption that the large eddies containing most of the turbulent energy

* Reeeived, Auguat 20th, 1957

** Department of Mechanical Engineering, Nihon University, Tokyo reach rapidly to the structural equilibrium specified by the type of shear. Such a kind of attack seems to be most powerful in the study of turbulent shear flows. Much remains to be done, however, before arriving at a thorough understanding of the mechanism of flow. An attempt has therefore been made to perform detailed measurements on the turbulent wake behind a circular cylinder without and with the presence of the turbulence produced by a grid.

- The work was carried out at the Department of Mechanical Engineering, Nihon University, as a part of the turbulence study group headed by Professor I. Tani, and partially supported by a research grant of the Ministry of Education. The author wishes to express his indebtedness 
to Professor Tani for the suggestions and advices given throughout the work. His acknowledgement is also due to Professor H. Kimura for the continued interest and encouragement. The author is indebted to. Mr. S. Akiyama for his efficient assistance in carrying out the experiments.

\section{Symbols}

$x, y, z$ Cartesian coordinates, its origin being located at the intersection of the axis of cylinder and median plane. $x$ is measured downstream in the direction of free stream. $z$ is measured along the axis of cylinder. $y$ is measured in the direction normal to the $(x, z)$ plane.

- $d$ diameter of cylinder, $1 \mathrm{~mm}$.

$U$ mean velocity.

$U_{0}$ free-stream velocity, $10 \mathrm{~m} / \mathrm{s}$.

$U_{c} \quad$ mean velocity at the center of wake.

$u \quad x$-component of fluctuating velocity.

$\overline{u^{2}} \quad x$-component of turbulent intensity.

$\overline{u^{2}} \quad \overline{u^{2}}$ at the center of wake.

$\overline{u^{2}}{ }_{w} \quad \overline{u^{2}}$ within turbulent fluid of wake.

$\overline{u_{f}^{2}} \quad \overline{u^{2}}$ in the outside free stream.

$\overline{u v} \quad$ turbulent shear stress.

$\overline{u v}_{w} \quad \overline{u v}$ within turbulent fluid of wake.

$\lambda=\overline{u^{2}} / \overline{(\partial u / \partial x)^{2}}$.

$b$ width of wake.

$L_{d} \quad=\left(\overline{u^{2}}\right)^{3 / 2} U_{0} /\left(\overline{d u^{2}}{ }_{f} / d x\right)$.

$\gamma$ - intermittency factor.

\section{Experimental Equipments}

An Eiffel type wind tunnel was used having a $60 \times 60 \mathrm{~cm}$ closed working section. The intensity of the background free-stream turbulence was about 0.17 percent. The turbulence intensity could be increased by placing a standard biplane grid at the entrance to the working section. The grid was composed of circular rods of $2 \mathrm{~mm}$ diameter with the mesh length of $10 \mathrm{~mm}$.

All the measurements were made in the wake of a circular cylinder of $1 \mathrm{~mm}$ diameter placed -at a distance $30.5 \mathrm{~cm}$ downstream from the entrance to working section. The, free-stream velocity was always $10 \mathrm{~m} / \mathrm{s}$.

The turbulence produced by the grid was as- certained to be uniform in the $y$-direction, and the downstream developments of the turbulence intensity $\overline{u^{2}}$ and the dissipation scale $\lambda$ were found to satisfy the conditions of isotropic turbulence. The turbulence intensity $\overline{u^{2}}$ and the decay scale $L_{d}$ that is approximately equal to the integral scale ${ }^{7)}$ are shown in figure 1.

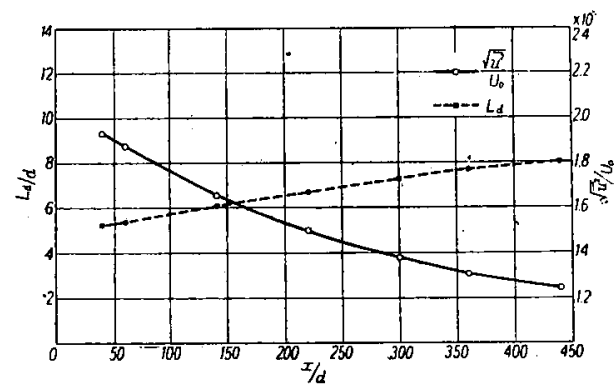

Fig. 1. Downstream development of the turbulence by grid

The hot-wire equipment used for the measurement was of similar performance as that of Kovasznay $^{8}$, and a 5 micron platinum-rhodium wire of $1.5 \mathrm{~mm}$ length was used as the sensing element.

\section{Experimental Procedure and Results}

All the measurements on the wake were made for the two cases; the one when the free stream was undisturbed, and the other when it was disturbed by the above mentioned grid.

The mean velocity distributions determined by a small total-head tube across the typical transverse sections are shown in figures 2 and 3 . In figure 4 are shown the mean velocity defect $U_{0}-U_{c}$ at the wake center and the wake width

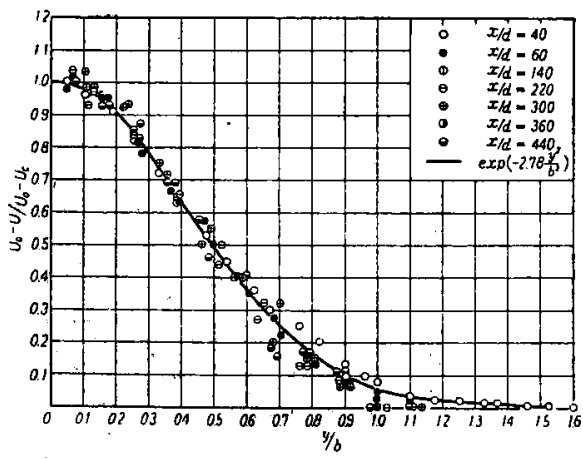

Fig. 2. Lateral distribution of mean velocity for undisturbed free stream 
$b$ defined as $1 / 2 \cdot\left(U_{0}-U_{c}\right)=U_{0}-U(1 / 2 \cdot b)$.

Measurements of turbulence were made across seven transverse sections in the wake, 40,60 , $140,220,300,360$ and 440 cylinder diameters downstream from the cylinder. Figures 5 and

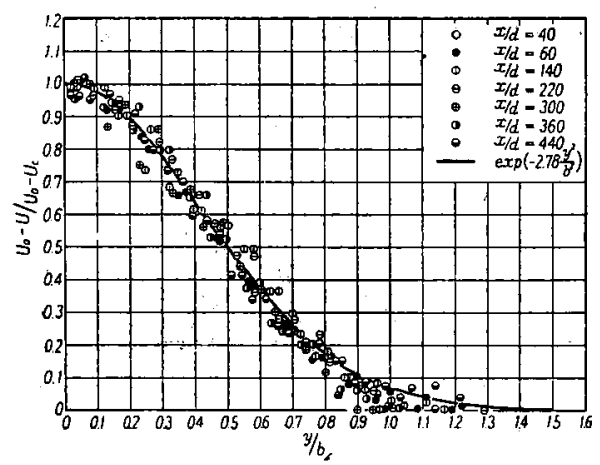

Fig. 3. Lateral distribution of mean velocity for disturbed free stream

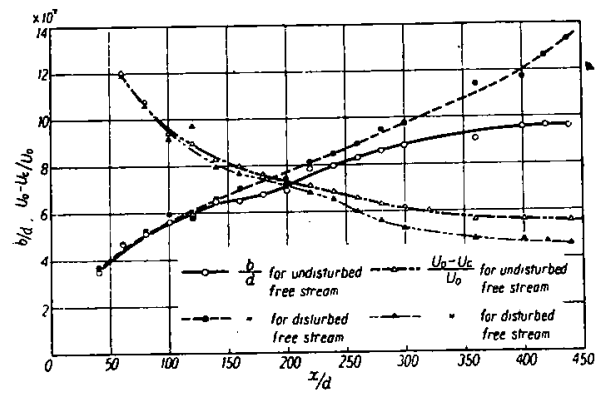

Fig. 4. Downstream developments of velocity defect and width

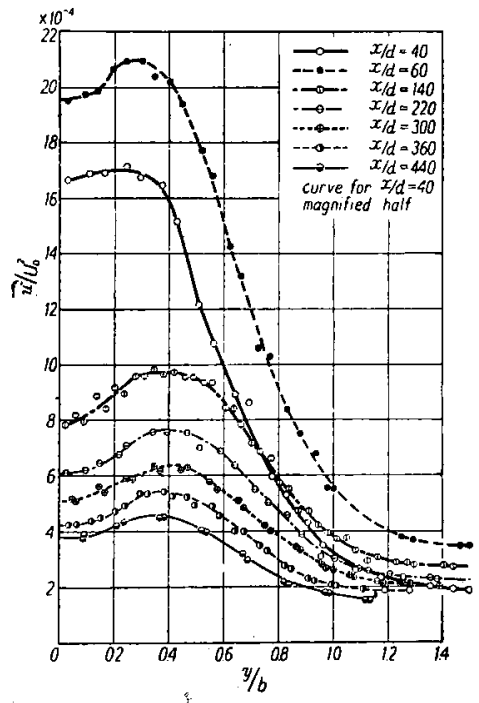

Fig. 5. Lateral distribution of turbulent intensity for disturbed frae stream
6 show the $x$-component of turbulence intensity $\overline{u^{2}}$. Distributions of turbulent shear stress $-\overline{u v}$ determined by using a single hot-wire inclined to free-stream direction are shown in figures 7 and 8 . The determination of $\overline{u^{4}}$ was made by feeding the hot-wire signal into a compensated amplifier, the output from which was then squared. Squaring circuit was based on the

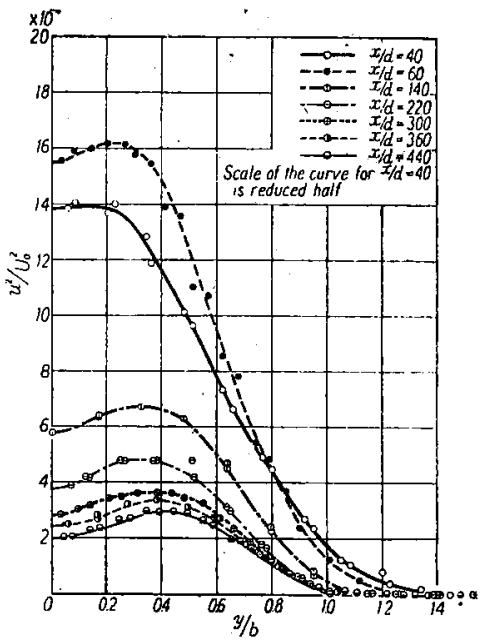

Fig. 6. Lateral distribution of turbulent intensity for undisturbed free stream

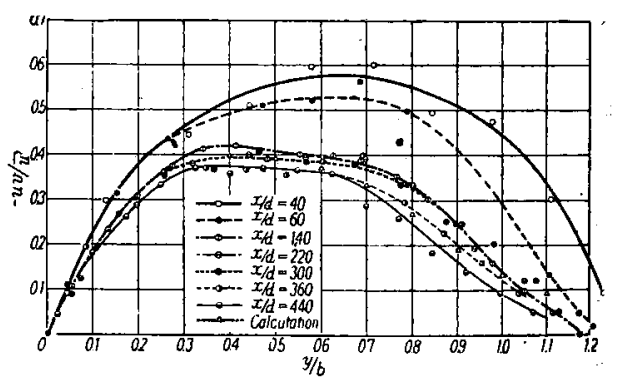

Fig. 7. Lateral distribution of shear coefficient for disturbed free stream

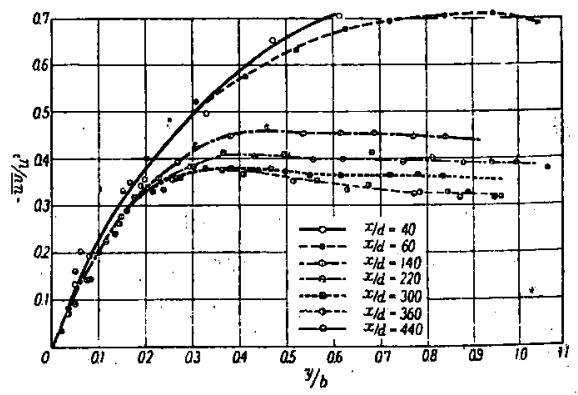

Fig. 8. Lateral distribution of shear coefficient for undisturbed free stream 
nonlinear characteristics of two balanced triodes. The squared signal was finally fed into an ordinary square meter. The results are presented in the form of the flatness factor $\overline{u^{4}} /{\overline{u^{2}}}^{2}$ in

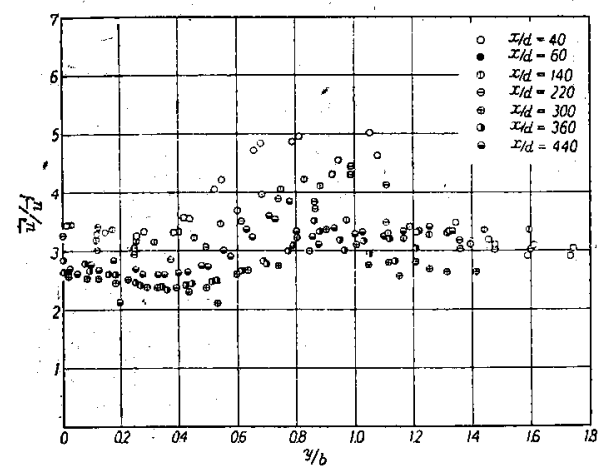

Fig. 9. Lateral distribution of flatness factor for disturbed free stream

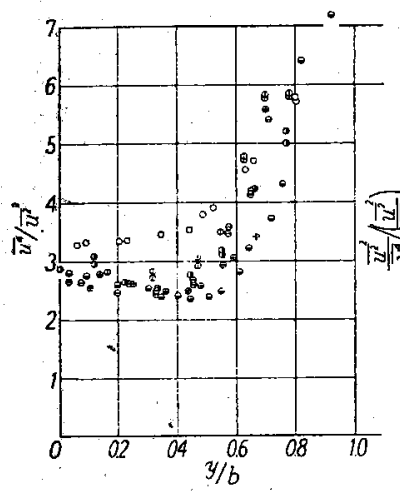

Fig. 10. Lateral distribution of flatness factor for undisturbed free stream

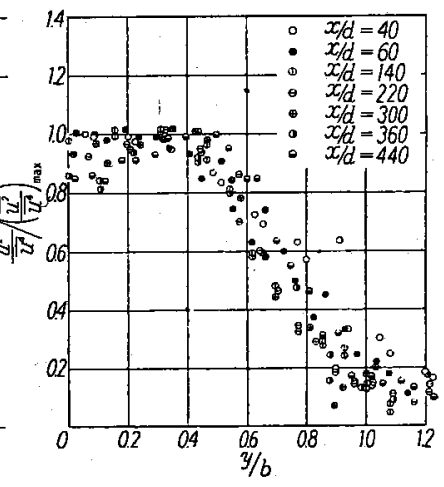

Fig. 11. Lateral distribution of $\left(\overline{u^{2}} / \overline{u^{4}}\right) /\left(\overline{u^{2}} / \overline{u^{4}}\right)_{\max }$ for undisturbed free stream figures 9 and 10. The determination of $\left(\overline{\partial u / \partial x)^{2}}\right.$ was obtained by electronically differentiating the hot-wire signal and making Taylor's assumption $\partial / \partial x=\partial / U \partial t^{9), 10)}$. The results are shown in the form $\lambda^{2}=\overline{u^{2}} / \overline{(\partial u / \partial x)^{2}}$ in figures 12 and 13 .

\section{Discussions and Considerations}

Velocity distribution The velocity distributions for distances 40 to 440 diameters downstream are best fitted with an error curve as shown by the solid line in figures 2 and 3 , both for the undisturbed and disturbed free streams. This leads us to consider that the structure of turbulence in a wake is scarcely affected by the turbulence of the outside free stream. The width of the wake as well as its rate of increase are larger than those in the case of the undisturbed free stream (figure 4).

Turbulence intensity As shown in figures 5 and 6 , the turbulence intensity is increased by the freestream turbulence. In order to demonstrate clearly the effect of freestream turbulence, comparisons were presented in figure 14(a) of the excess of turbulence intensity at the wake center above that of the outside free stream in terms of the intensity of the mean velocity variation, $\left(\overline{u^{2}}-\overrightarrow{u_{f}^{2}}\right) /$ $\left(U_{0}-U_{c}\right)^{2}$. The curves for the undisturbed and disturbed free streams.

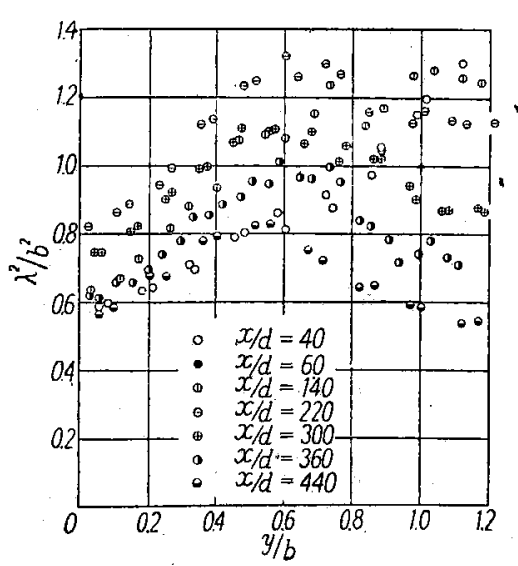

Fig. 12. Lateral distribution of $\lambda^{2} / b^{2}$ for disturbed free stream

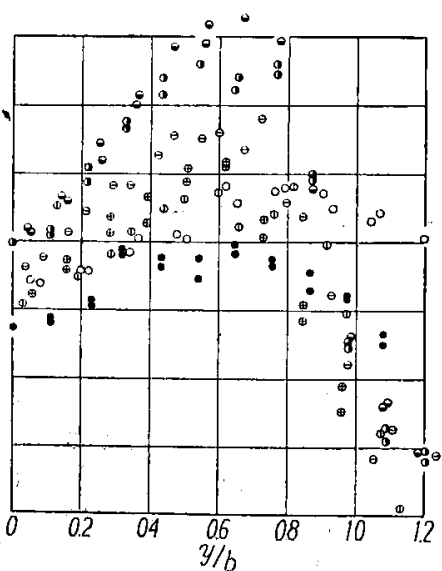

Fig. 13. Lateral distribution of $\lambda^{2} / b^{2}$ for undisturbed free stream 

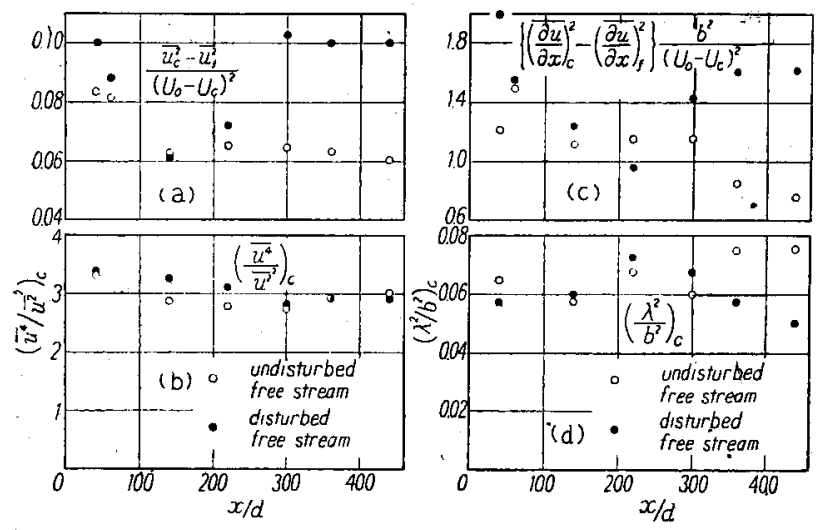

Fig. 14. Developments of turbulence at the center of wake

agree well each other for distances smaller than 300 diameters downstream, while for distances greater than 300 diameters the effect of freestream turbulence more or less changes the structure of turbulent wake.

Flatness factor For the undisturbed free stream the flatness factor suffers inappreciable downstream variation, only the minimum of the curve shifting outward and tending to the location $y / b=0.35$ for distances greater than 300 diameters as shown in figure 10. The reciprocal of the flatness factor, normalized in the form $\left(\overline{u^{2}} / \overline{u^{4}}\right) /\left(\overline{u^{2}} / \overline{u^{4}}\right)_{\text {max }}$, is presented in figure 11 . This quantity should agree with the intermittency factor, provided that the non-turbulent fluid between the instantaneous boundaries of the wake contributes nothing to the flatness factor. It has already been known that this is the case ${ }^{a)}$, so that the above mentioned ratio essentially represents the flatness factor.

In the case of disturbed free stream, the dis. tribution of the flatness factor behaves apparently differently. However, this is simply because of the fact that the flatness factor of the outside isotropic turbulence has a value of approximately 3. As a matter of fact, the flatness factor agrees with that of the undisturbed free stream within the central part of the wake and tends to 3 as the location is approached to the edge of wake. For the sake of easier understanding, the flatness factor at the wake center is shown both for the undisturbed and disturbed free streams (figure 14(b)). The agreement of the curves for both cases appears to suggest the negligible influence of the free-stream turbulence on the large eddies responsible for $\overline{u^{4}}$.

Turbulent shear stress The turbulent shear stress depends primarily on the structure of large eddies. Therefore the shear coefficient $-\overline{u v} \sqrt{u^{2}}$ is expected to give an insight into the structure of large eddies.

As shown in figure 8, the shear coefficient for the undisturbed free stream becomes nearly constant, having numerical values 0.35 to 0.40 , across various transverse sections at distances greater than 140 diameters downstream. On the other hand, in the case of disturbed free stream the outside turbulence is isotropic so that it contributes only to turbulence intensity but not to shear stress. As a matter of fact, the shear coefficient rapidly decreases to zero as the location is approached to the edge of wake (figure 7).

According to the conception of intermittent nature of the wake, the shear coefficient might be given by

$$
\frac{\overline{u v}}{\overline{u^{2}}}=\frac{\overline{u v}_{w}}{\overline{u^{2}}{ }_{w}}\left(1-\frac{1-\gamma}{\gamma} \frac{\bar{u}_{f}}{\bar{u}_{w}^{2}}\right)^{-1}
$$

where the subscripts $f$ and $w$ denote the quantities related to the outside free stream and turbulent fluid of wake, respectively. By estimating the intermittency factor $r$ from the mean curve of $\left(\overline{u^{2}} / \overline{u^{4}}\right) /\left(\overline{u^{2}} / \overline{u^{4}}\right)_{\text {max }}$ shown in figure 11 for the undisturbed free stream and assuming that $-\overline{u v}_{w}=0.4$, it is possible to calculate shear coefficient by the above equation. The results are shown by triangles in figure 7 , and it is seen that the agreement between calculated and measured values is very good.

This agreement, together with the coincidence of the flatness factors at the wake center both in undisturbed and disturbed free streams, seems to suggest that the structure of large eddies are scarcely affected by the free-stream turbulence.

Dissipation scale The quantity $\lambda$, representing the dissipation scale in isotropic turbulence, has been known to approximately correspond to the dissipation scale also in a wake. Thus the ratio 
$\lambda / b$ might give a rough measure of the nature of small eddies responsible for viscous dissipation.

As shown in figure $13, \lambda / b$ for the undisturbed free stream increases downstream at small distances, but tends to a certain universal distribution when the distance exceeds about 360 diameters. The universal character of the distribution of $\lambda / b$ (figure 13) as well as that of $\overline{u v} / \overline{u^{2}}$ (figure 8) at far distances downstream demonstrate the similarity of the structure of turbulent wake.

For the disturbed free stream the distribution of $\lambda / b$ within the central part of the wake approximately agrees with that for the undisturbed free stream and tends to the value of the outside free stream as the location is approached to the edge of wake for distances smaller than 300 diameters downstream. But for distances greater than 300 diameters the value of $\lambda / b$ within the central part of wake decreases downstream (figure 12), contrary to the case for the undisturbed free stream. It seems that the structure of small eddies is appreciably affected by the free-stream turbulence at far distances downstream.

This result can be explained in the following way. As mentioned above (figures 4 and 14(a)), the structure of large eddies playing the main role for the turbulent energy production is scarcely affected by the outside free-stream turbulence and both the width of wake and the excess of turbulent energy above that of the outside freestream turbulence in terms of the intensity of mean velocity variation increase appreciably for distances greater than 300 diameters downstream. This circumstance naturally results in the increase of the rate of turbulent energy production. Thus, the dissipation scale $\lambda / b$ should decrease in such a way that the production and dissipation of turbulent energy are balanced with each other.

\section{Conclusions}

The measurements on the turbulent wake disturbed by the free-stream turbulence having the scale comparable to the wake width suggest the following effects of outside free-stream turbulence:

1. The width of the wake as well as its rate of increase rapidly increase for distances greater than 300 diameters downstream.

2. The intensity of turbulence increases.

3. The shear coefficient and flatness factor, both of which are related to large eddies, suffer no substantial change. The observed change is of apparent nature.

4. The dissipation scale correlated with small eddies suffers substantial change for distances greater than 300 diameters downstream.

5. The items (3) and (4) suggest the rapid approach of large eddies toward the structural equilibrium similar to that for the undisturbed free stream in spite of the substantial change in small eddies.

\section{References}

1) Townsend, A. A. : Measurements in the Turbulent Wake of a Cylinder. Proc. Roy. Soc., A, vol. 190, 1947, pp. 651-561.

2) Townsend, A. A.: Local Isotropy in the Turbulent Wake of a Cylinder. Aust. J. Sci. Res., vol. 1, 1948, pp. 161-174.

3) Towngend, A. A.: Momentum and Energy Diffusion in the Turbulent Wake of a Cylinder. Proc. Roy: Soc., A, vol. 197, 1949, pp. 124-140.

4) Towneend, A. A.: The Fully Developed Turbulent Wake of a Circular Cylinder. Aust. J. Sci. Res., vol. 2, 1949, pp. 451-468.

5) Townsend, A. A.: The Structure of Turbulent Shear Flow. Cambridge University Press 1956.

6) Correin, S.: Investigations of Flow in an Axially Symmetric Heated Jet of Air. NACA ACR 3L23, 1943, declassified as NACA Wartime Report W-94.

7) Batchelor, G. K. : The Theory of Homogeneous Turbulence. Cambridge University Press 1958.

8) Kovagznay, L.S. G.: Development of TurbulenceMeasuring Equipment. NACA Tech. Note no. 2839, 1958.

9) Taylor, G. I.: The Spectrum of Turbulence. Proc. Roy. Soc., A, vol. 164, 1988, pp. 476-490.

10) Lin, C.C.: On Taylor's Hypothesis and the Acceleration Terms in the Navier-Stokes Equationg. NAVORD Rep. no. 2306, 1952. 